\title{
Gendered walkability: Building a daytime walkability index for women
}

\author{
Yael Golan \\ San Francisco State University \\ yaelg@mail.sfsu.edu \\ Jason Henderson \\ San Francisco State University \\ jhenders@sfsu.edu
}

\author{
Nancy Lee Wilkinson \\ San Francisco State University \\ nancyw@sfsu.edu \\ Aiko Weverka \\ San Francisco State University \\ aweverka@gmail.com
}

\begin{abstract}
Urban walkability is influenced both by built environment features and by pedestrian demographics. Research has shown that factors influencing women's walking differ from those affecting men's. Using a mixed-method approach, this study creates a new women-specific, GIS-based walkability index using San Francisco as a case study, and answers two questions: Which variables most influence women's propensity to walk? And Does the leading walkability index, Walk Score, reflect women's walkability? Focus group participants $(\mathrm{n}=17)$ ranked crime, homelessness and street/sidewalk cleanliness as the three most influencing factors on women's walkability, accounting for $58 \%$ to $67 \%$ of the Women's Walkability Index's total score. The least walkable areas in San Francisco, according to this index, are rated as some of the most walkable neighborhoods in the city by Walk Score, despite high crime and homelessness density. Walk Score is negatively correlated with the new Women's Walkability Index (Spearman's rho $=-0.585$ ) and inaccurately represents women's walkability. If the new index accurately captures the reality of women's walking, then some of the most widely accepted conventions about what kind of areas promote walking could be inaccurate when it comes to women.
\end{abstract}

\section{Article history:}

Received: October 12, 2018

Received in revised form:

April 7, 2019

Accepted: May 6, 2019

Available online: June 25, 2019

Data availability: https://datasf

.org/opendata/

\section{Introduction}

Urban walkability has been linked to many benefits, including increased levels of physical activity (Calise, Heeren, DeJong, Dumith, \& Kohl, 2013; Durand, Andalib, Dunton, Wolch, \& MA, 2011; Frank et al., 2006), improved economic performance (Cortright, 2009; Leinberger \& Alfonzo, 2012); and some environmental benefits, including a reduction in vehicle miles traveled (Diao \& Ferreira, 2014; Frank et al., 2006; Talen \& Koschinsky, 2014) and lower levels of hazardous air pollution (Frank et al., 2006; Zahran, Brody, Maghelal, Prelog, \& Lacy, 2008).

An area's walkability is largely influenced by built environment features like pedestrian amenities, land-use mix and proximity to destinations, and also by individual characteristics like the level of familiarity with the area, age and gender. With the aid of Geographic Information Systems (GIS) and other advanced technologies, researchers can now measure and model the physical and built-environment

Copyright 2019 Yael Golan, Nancy Lee Wilkinson, Jason Henderson, \& Aiko Weverka http://dx.doi.org/10.5198/jtlu.2019.1472

ISSN: 1938-7849 | Licensed under the Creative Commons Attribution - Noncommercial License 4.0

The Journal of Transport and Land Use is the official journal of the World Society for Transport and Land Use (WSTLUR) and is published and sponsored by the University of Minnesota Center for Transportation Studies. 
features that influence walkability better than ever before (Leslie et al., 2007), though the question of how specific personal characteristics influence walking remains largely unanswered.

One prominent online tool applying modern technology to analyze walkability is Walk Score, which uses a distance decay function to rank the walkability of an address based on its proximity to nearby destinations such as restaurants and retail (Walk Score, n.d.). Walk Score is considered by some academics a reliable proxy for neighborhood walkability and has been validated as such by several studies. Manaugh \& El-Geneidy (2011) compared four existing walkability indices at multiple geographic scales with actual observed travel behavior for over 44,200 home-based trips in Montreal and found that all four walkability indices performed well in describing pedestrian behavior, though Walk Score proved to be slightly superior to the other indices at predicting whether a home-based shopping trip would be made on foot. Duncan, Aldstadt, Whalen, \& Melly (2012) tried to validate Walk Score as a measure of neighborhood walkability and found that while it accurately captures features like retail and open space density, intersection density and residential density, it does not account for other aspects of walkability, like sidewalk completeness and average speed limit (Park et al., 2012). Walk Score has been criticized for focusing solely on flexible, leisure-time activities, and ignoring fixed activities like work and childcare (Vale, Saraiva, \& Pereira, 2015). Carr, Dunsiger, \& Marcus (2010) explored Walk Score's validity as a walkability index and found strong and significant correlations between Walk Score and all objective measures of the physical environment assessed in their study, but also found positive correlations between Walk Score and reported crime, suggesting that walkability-inhibiting factors may not be reflected by the index (Koschinsky \& Talen, 2015).

Despite the richness of available data and the large volume of current research on walkability, the study of gender differences in walking remains limited, especially in the context of built environment attributes, (Owen, Humpel, Leslie, Bauman, \& Sallis, 2004), with the exception of studies focusing on walking for exercise (Durand et al., 2011; Kerr et al., 2014; Van Dyck et al., 2015) or on the associations between walkability and health-related measures in women (Sugiyama, Salmon, Dunstan, Bauman, \& Owen, 2007). Studies that do focus on gender in the context of built environment features generally point to substantial differences between men and women in regards to their sensitivity to such aspects as traffic (Clifton \& Livi, 2005), sidewalks (Brookfield \& Tilley, 2016; Clifton \& Dill, 2005), neighborhood aesthetics (Pelclová, Frömel, \& Cuberek, 2013) and other built environments and streetscape features (Owen et al., 2004; Park \& Calvert, 2008). Fear of violent crime has been a dominant theme in research on women's relationship with public spaces, built environment characteristics and walking (Koskela \& Pain, 2000; Loukaitou-Sideris, 2006; Pain, 2001; Valentine, 1989), but little attention has been given to the gendered patterns of walking outside of women's fear of crime. The limited academic attention to women's pedestrian experiences points to a gap in our understanding of both walkability and women's mobility.

This study aims to address this gap by exploring women's subjective pedestrian experiences and creating a women-specific walkability index focusing on daytime walking, when fear of crime is assumed to be less pronounced. By employing a mixed-method approach comprised of focus groups, GIS and statistical analysis, two research questions are explored: Which variables most influence women's propensity to walk? And Does the leading walkability index, Walk Score, reflect women's walkability?

\section{$2 \quad$ Methods}

\section{$2.1 \quad$ Study area}

San Francisco is consistently ranked the second most walkable large city in the U.S. (Walk Score, 2016) — and has a culture of walking, with almost a quarter of daily trips made on foot (SFMTA, 
2014), a much larger share than the national average of about 10\% (U.S. Department of Transportation, 2011). It is a stated goal of the city to further improve walking conditions (San Francisco Planning Department, 2011).

Understanding the mechanisms and built-environment features that influence women's propensity to walk in a walkable city like San Francisco can have important implications for the ability of urban planners and policy makers — locally, regionally and nationally— to improve female residents' pedestrian experience, increase overall walkability, and create better, more pedestrian-friendly environments that encourage walking over driving, for both genders.

\section{$2.2 \quad$ Focus groups}

Two focus groups were held in fall 2016. Each meeting took about 90 minutes, and a total of seventeen women participated. Participants were recruited using snowball sampling, with a recruitment message sent via email and posted on the Nextdoor neighborhood social network in 31 San Francisco neighborhoods. Participants were female residents of San Francisco over the age of eighteen who had been San Francisco residents for at least three months and did not reside in on-campus housing in a school, hospital, or military base. Participants were not paid for their participation.

Focus group participants were encouraged to discuss daytime walking and ignore nighttime walking, which is both less prevalent (Cervero \& Duncan, 2003; Clifton \& Livi, 2005) and more heavily influenced by fear of crime (Loukaitou-Sideris, 2006). An emphasis was placed on participants' day-today walking for transit, leisure and errands, as opposed to walking for exercise. Participants were asked to describe and discuss positive and negative walking experiences, favorite and least favorite routes, and what affects them the most when walking or making walking-related decisions, like route choice. Participants were also asked to discuss the importance of ten index variables selected by the researcher a priori based on an extensive literature review pointing to fear of crime, safety from traffic, and safe sidewalk conditions as key components of women's walkability. The majority of variables included in the index and discussed by participants represent these three main concerns, with the addition of the types of businesses on the street. The ten variables discussed included sidewalk quality, sidewalk cleanliness, crime, presence of parks, presence of homeless people or encampments, vehicular traffic speed, graffiti, off-street parking, Americans with Disabilities Act (ADA) curb ramps, and types of businesses that deterred or promoted women's walking.

At the end of each focus group meeting, participants were asked to fill out a prioritizing grid based on Pairwise Comparison (Figure 1), a method for comparing alternatives in pairs to judge which of each

pair is preferred. In this case, the alternatives compared were the ten variables discussed at focus group meetings, and participants were asked to choose, for each pair of variables, the one that had a stronger effect on their walking. The number of times each variable was chosen as the more important one was summarized across all participants and the variables were ranked accordingly, resulting in an aggregate ranking of all ten variables based on focus group participants' preferences. 


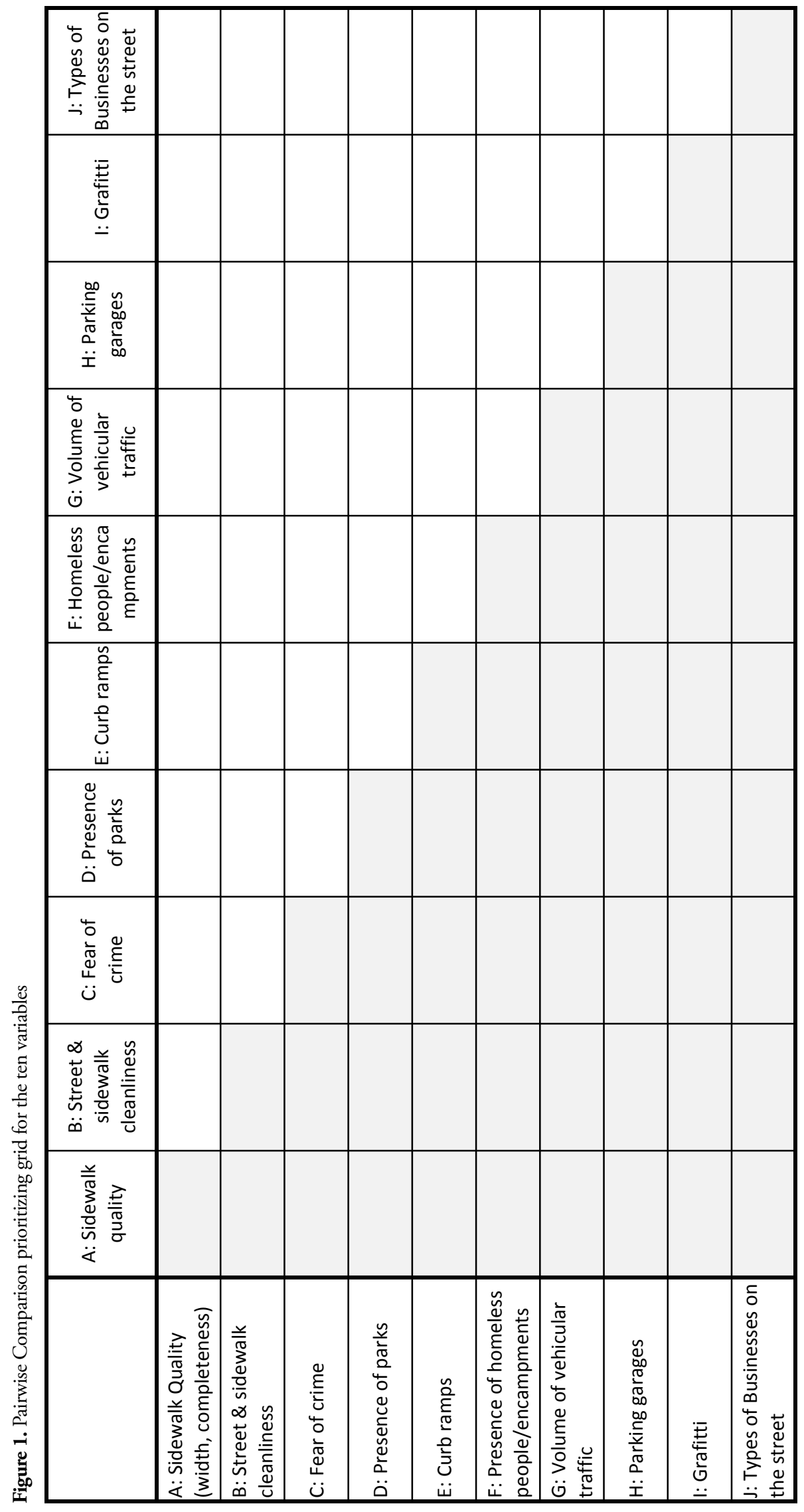


The Analytical Hierarchy Process (AHP) (Saaty, 2008) was then used to transform the Pairwise Comparison-based ordinal rankings into mathematical weights that could be used to assign relative importance of spatial data layers in GIS. AHP measures the relative importance of each pair of variables on a scale of 1 to 9 (Figure 2). Here, the AHP scale was used to measure the relative importance of each pair of variables across all participants:

\begin{tabular}{c|ll}
\multicolumn{1}{c}{$\begin{array}{l}\text { Intensity of } \\
\text { Importance }\end{array}$} & \multicolumn{1}{c}{ Definition } & \multicolumn{1}{c}{ Explanation } \\
\hline 1 & Equal importance & $\begin{array}{l}\text { The two variables A, B, equally influence walking } \\
\text { (half of the participants chose A over B) }\end{array}$ \\
\hline 3 & $\begin{array}{l}\text { Weak importance } \\
\text { of one over the }\end{array}$ & $\begin{array}{l}\text { Variable A is slightly more influential than B } \\
\text { (11 of 17 participants chose A over B) }\end{array}$ \\
\hline 5 & $\begin{array}{l}\text { Essential or } \\
\text { strong importance }\end{array}$ & $\begin{array}{l}\text { Variable A is more influential than B } \\
\text { (13 of 17 participants chose A over B) }\end{array}$ \\
\hline 7 & $\begin{array}{l}\text { Demonstrated } \\
\text { importance }\end{array}$ & $\begin{array}{l}\text { Variable A is much more influential than B } \\
\text { (15 of 17 participants chose A over B) }\end{array}$ \\
\hline $2,4,6,8$ & $\begin{array}{l}\text { Absolute } \\
\text { Intermediate values between the two adjacent statements }\end{array}$ \\
\hline Reciprocals of \\
above
\end{tabular}

Figure 2. The scale of relative importance (based on Saaty, 2008)

Once the relative importance of each variable was calculated (Figure 3), variable weights were derived by dividing the value assigned to the choice $A$ vs. $B$ by the sum of values for all choices regarding A (A vs. C, A vs. D, etc.), and making equal to 1 the sum of entries on each column. Variable weights were then calculated by averaging the entries on each row, with the sum of all weights totaling $100 \%$. 


\begin{tabular}{|c|c|c|c|c|c|c|c|c|c|c|}
\hline 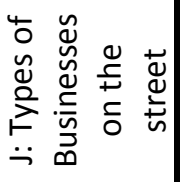 & $\stackrel{m}{m}$ & $\begin{array}{l}\text { ○ } \\
\text { - }\end{array}$ & $\stackrel{8}{\circ}$ & $\underset{-}{8}$ & $\stackrel{m}{\stackrel{n}{0}}$ & ஜ & $\underset{\text { i }}{\text { i }}$ & ન̆ & ને & $\underset{\text { ¿ }}{\text { ¿ }}$ \\
\hline $\begin{array}{l}\stackrel{ \pm}{+\frac{\pi}{\pi}} \\
\frac{\pi}{0} \\
\ddot{-}\end{array}$ & ষ্் & ஜ & \& & $\underset{\infty}{\stackrel{\infty}{\infty}}$ & $\stackrel{\text { ָ̦ }}{\circ}$ & ৪ & $\underset{\infty}{8}$ & $\underset{i}{8}$ & $\underset{\text { i }}{8}$ & $\underset{0}{8}$ \\
\hline 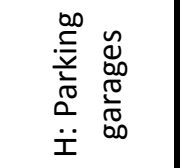 & $\underset{m}{\stackrel{8}{m}}$ & ¿ & $\underset{\infty}{\stackrel{\infty}{0}}$ & ه & ָৃ & $\begin{array}{l}8 \\
\infty\end{array}$ & ه্ & $\underset{\text { i }}{\text { ¿ }}$ & 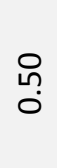 & $\begin{array}{l}8 \\
0\end{array}$ \\
\hline 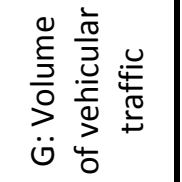 & $\stackrel{\text { ণ }}{0}$ & $\underset{\text { 이 }}{\text { in }}$ & $\begin{array}{l}8 \\
0\end{array}$ & $\underset{\text { - }}{8}$ & $\stackrel{m}{\stackrel{m}{0}}$ & $\begin{array}{l}\stackrel{8}{\circ} \\
\stackrel{+}{ }\end{array}$ & $\underset{-}{8}$ & ન્- & $\stackrel{m}{\stackrel{-}{0}}$ & $\begin{array}{l}\text { 유 } \\
\text { ○े }\end{array}$ \\
\hline 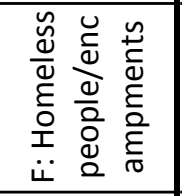 & ने & $\stackrel{\stackrel{\llcorner}{0}}{0}$ & 8 & $\stackrel{m}{m}$ & $\vec{\jmath}$ & $\underset{-}{8}$ & $\stackrel{\stackrel{L}{\sim}}{0}$ & $\stackrel{m}{\stackrel{n}{0}}$ & $\stackrel{\overrightarrow{1}}{\overrightarrow{0}}$ & ને \\
\hline 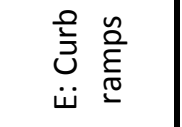 & $\underset{\infty}{\stackrel{\infty}{\infty}}$ & $\begin{array}{l}8 \\
\text { वे }\end{array}$ & $\begin{array}{l}8 \\
\infty \\
\infty\end{array}$ & $\begin{array}{l}8 \\
0\end{array}$ & $\underset{\text { i }}{8}$ & $\begin{array}{l}8 \\
\text { के }\end{array}$ & $\begin{array}{l}8 \\
\infty \\
\infty\end{array}$ & $\begin{array}{l}8 \\
\text { ம் }\end{array}$ & $\begin{array}{l}8 \\
\text { in }\end{array}$ & $\begin{array}{l}8 \\
\infty \\
\infty\end{array}$ \\
\hline 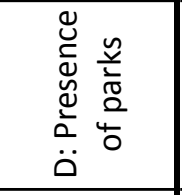 & $\stackrel{\stackrel{\llcorner}{n}}{0}$ & & ஜ & $\underset{\text { i }}{8}$ & $\stackrel{-1}{\stackrel{-}{0}}$ & $\begin{array}{l}8 \\
\dot{m}\end{array}$ & $\underset{-}{8}$ & 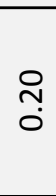 & $\stackrel{m}{-}$ & $\underset{\text { ¿ }}{8}$ \\
\hline 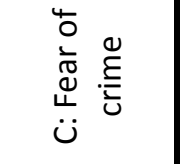 & ন্- & $\stackrel{\sim}{\stackrel{4}{0}}$ & $\underset{-}{\stackrel{-}{8}}$ & ને & $\stackrel{m}{\stackrel{m}{0}}$ & ণָ & ને & $\stackrel{m}{\dddot{0}}$ & $\stackrel{-1}{\circ}$ & $\stackrel{\stackrel{J}{二}}{\circ}$ \\
\hline 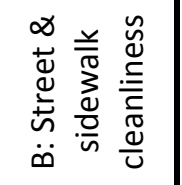 & ને & ه্ & $\stackrel{8}{i}$ & $\underset{-i}{8}$ & ન્- & $\underset{+}{\stackrel{\leftrightarrow}{\circ}}$ & 웅 & $\underset{\sim}{\stackrel{+}{\sigma}}$ & $\underset{0}{-1}$ & ¿ \\
\hline \multirow[t]{2}{*}{ 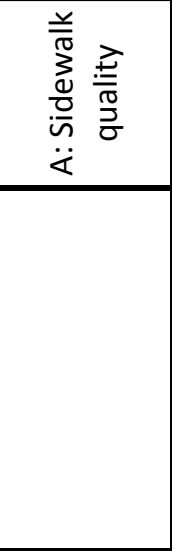 } & $\underset{-}{8}$ & 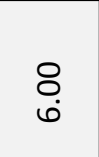 & ৪ & $\underset{+}{\stackrel{\leftrightarrow}{+}}$ & $\stackrel{m}{\stackrel{m}{0}}$ & $\underset{\emptyset}{8}$ & ه & $\underset{m}{m}$ & $\stackrel{\text { ָ̦ }}{0}$ & $\begin{array}{l}\text { O } \\
\text { in }\end{array}$ \\
\hline & 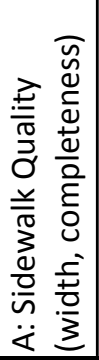 & 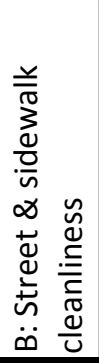 & 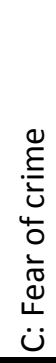 & 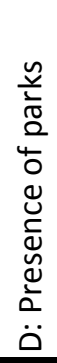 & 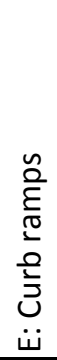 & 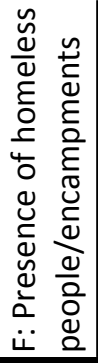 & 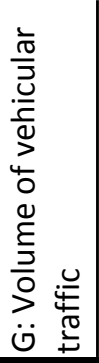 & 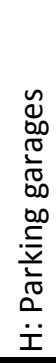 & 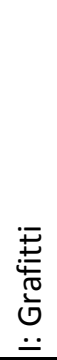 & 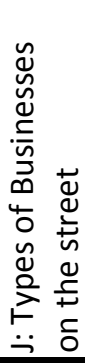 \\
\hline
\end{tabular}




\subsection{Data and variables}

The Women's Walkability Index (WWI) was created using ArcGIS software version 10.4.1 (ESRI, Redlands, CA). In addition to the ten variables ranked by focus group participants, slope was added as an eleventh variable to account for San Francisco's hilly terrain. Participants in both groups noted that slope was an influential factor in their walking behavior. However, since it was not part of the original prioritizing grid, slope was not given a rank by participants and a corresponding AHP weight. To solve this, slope was added to the AHP analysis as an eleventh variable and given a median rank, as if half of the women found it more important than other variables, and half of the women did not. This was done after all other variable rankings and weights had been calculated, to allow for an analysis both with and without slope. This provides an opportunity to see what the rankings for San Francisco would look like if the city were flat and allows for a replication of the index in other geographies that are not heavily influenced by slope without having to change variable rankings and weights.

The Sidewalk Quality variable was ultimately excluded from the GIS analysis, despite discussion by focus group participants, since sidewalk condition data for San Francisco was not available. Therefore, AHP weights had to be recalculated excluding the Sidewalk Quality variable.

All data sets were obtained from SF OpenData (https://data.sfgov.org), the open-access online portal for data published by the City \& County of San Francisco. For parking garages, parks, and speed limits, GIS shapefiles were available on the SF Open Data platform. The other data sets were downloaded as comma-separated value (CSV) files with location information. Latitude and longitude measurements were converted to spatial data and address data were geocoded using an ESRI 2013 US street address locator. Slope was derived from the 10-meter digital elevation model (DEM) of San Francisco obtained from the United States Geological Survey (USGS) website (https://viewer.nationalmap.gov/basic/). All datasets were re-projected and analyzed in the North American Datum (NAD) 1983 State Plane coordinate system. Since 266 city blocks did not have speed limit data, these blocks were excluded from the analysis altogether so that 14,507 of 14,773 city blocks were eventually scored by the index (98.2\%).

For the crime variable, only daytime crimes relevant to pedestrians and street life were included: assault, burglary, disorderly conduct, drug/narcotic, drunkenness, gang activity, liquor laws, loitering, prostitution, robbery, sex offenses, vandalism and vehicle theft. Other types of crimes, like fraud, arson, bribery etc. were excluded from analysis because it is assumed that they do not affect pedestrians. Additionally, crimes occurring between $8 \mathrm{pm}$ and 6am were excluded, due to this index's focus on daytime walkability.

For the "types of businesses" variable, registered business locations were divided into three categories based on the literature review and focus group discussions: 1) Walkability-promoting businesses such as retail, restaurants, coffee shops, grocery stores, physical fitness facilities, beauty salons, schools and childcare facilities; 2) Walkability-inhibiting businesses such as liquor stores, auto repair shops, gas stations, drinking places, warehouses and industrial activities; and 3) "Neutral" businesses that neither promote nor inhibit walkability, including accountants, banks, law offices and such.

Figure 4 describes the variables, measures, data sources and direction of influence of each measure on women's walking: negative (-) or positive (+). 


\begin{tabular}{|c|c|c|c|}
\hline Variable & Measure & $\begin{array}{l}\text { Direction of } \\
\text { Influence }\end{array}$ & $\begin{array}{c}\text { Data Source (City } \\
\text { Department) and Year }\end{array}$ \\
\hline Crime & $\begin{array}{l}\text { Number of daytime } \\
\text { "pedestrian affecting" } \\
\text { crimes per block }\end{array}$ & $(-)$ & $\begin{array}{l}\text { SF Police Department, } \\
2016 \text { data }\end{array}$ \\
\hline $\begin{array}{l}\text { Presence of } \\
\text { homeless people } \\
\text { or encampments }\end{array}$ & $\begin{array}{l}\text { Number of requests for } \\
\text { cleanup of encampments, } \\
\text { carts, needles or human } \\
\text { waste per block }\end{array}$ & $(-)$ & $\begin{array}{l}\text { SF } 311 \text { (customer } \\
\text { service), } 2016 \text { data }\end{array}$ \\
\hline $\begin{array}{l}\text { Street and } \\
\text { sidewalk } \\
\text { cleanliness }\end{array}$ & $\begin{array}{l}\text { Number of requests for } \\
\text { cleanup of street, garbage } \\
\text { cans, bulky items and } \\
\text { other waste per block }\end{array}$ & $(-)$ & $\begin{array}{l}\text { SF } 311 \text { (customer } \\
\text { service), } 2016 \text { data }\end{array}$ \\
\hline Vehicular traffic & $\begin{array}{l}\text { Maximum speed limit per } \\
\text { block (MPH) }\end{array}$ & $(-)$ & $\begin{array}{l}\text { SF Municipal } \\
\text { Transportation Agency, } \\
2016 \text { data }\end{array}$ \\
\hline $\begin{array}{l}\text { Parks \& open } \\
\text { space }\end{array}$ & $\begin{array}{l}\text { Presence of parks and } \\
\text { open spaces on or adjacent } \\
\text { to a block }\end{array}$ & $(+)$ & $\begin{array}{l}\text { SF Recreation \& Parks } \\
\text { Department, } 2016 \text { data }\end{array}$ \\
\hline \multirow{3}{*}{$\begin{array}{l}\text { Type of } \\
\text { businesses on the } \\
\text { street }\end{array}$} & $\begin{array}{l}\text { Number of walkability- } \\
\text { promoting businesses per } \\
\text { block }\end{array}$ & $(+)$ & \multirow{3}{*}{$\begin{array}{l}\text { SF Treasurer - Tax } \\
\text { Collector, } 2015 \text { data }\end{array}$} \\
\hline & $\begin{array}{l}\text { Number of walkability- } \\
\text { inhibiting businesses per } \\
\text { block }\end{array}$ & $(-)$ & \\
\hline & $\begin{array}{l}\text { Number of walkability-neut] } \\
\text { businesses per block }\end{array}$ & $(+)$ & \\
\hline $\begin{array}{l}\text { Off-street } \\
\text { parking lots and } \\
\text { parking garages }\end{array}$ & $\begin{array}{l}\text { Number of parking spaces } \\
\text { in off-street parking } \\
\text { garages and parking lots } \\
\text { per block }\end{array}$ & $(-)$ & $\begin{array}{l}\text { SF Municipal } \\
\text { Transportation Agency, } \\
2016 \text { data }\end{array}$ \\
\hline Graffiti incidents & $\begin{array}{l}\text { Number of reported } \\
\text { graffiti incidences per } \\
\text { block in last } 30 \text { days }\end{array}$ & $(-)$ & $\begin{array}{l}\text { SF } 311 \text { (customer } \\
\text { service), } 2016 \text { data }\end{array}$ \\
\hline $\begin{array}{l}\text { Curb ramps } \\
\text { (ADA) }\end{array}$ & $\begin{array}{l}\text { Number of curb ramps per } \\
\text { block }\end{array}$ & $(+)$ & $\begin{array}{l}\text { SF Department of Public } \\
\text { Works, } 2016 \text { data }\end{array}$ \\
\hline Slope & $\begin{array}{l}\text { Block slope (difference in } \\
\text { elevation between two } \\
\text { ends of the block) }\end{array}$ & $(-)$ & $\begin{array}{l}\text { United States Geological } \\
\text { Survey (USGS), } 2017\end{array}$ \\
\hline
\end{tabular}

Figure 4. Variables, measures, direction of influence and data sources

Figure 5 provides a visual step-by-step roadmap of the methodological steps taken. 


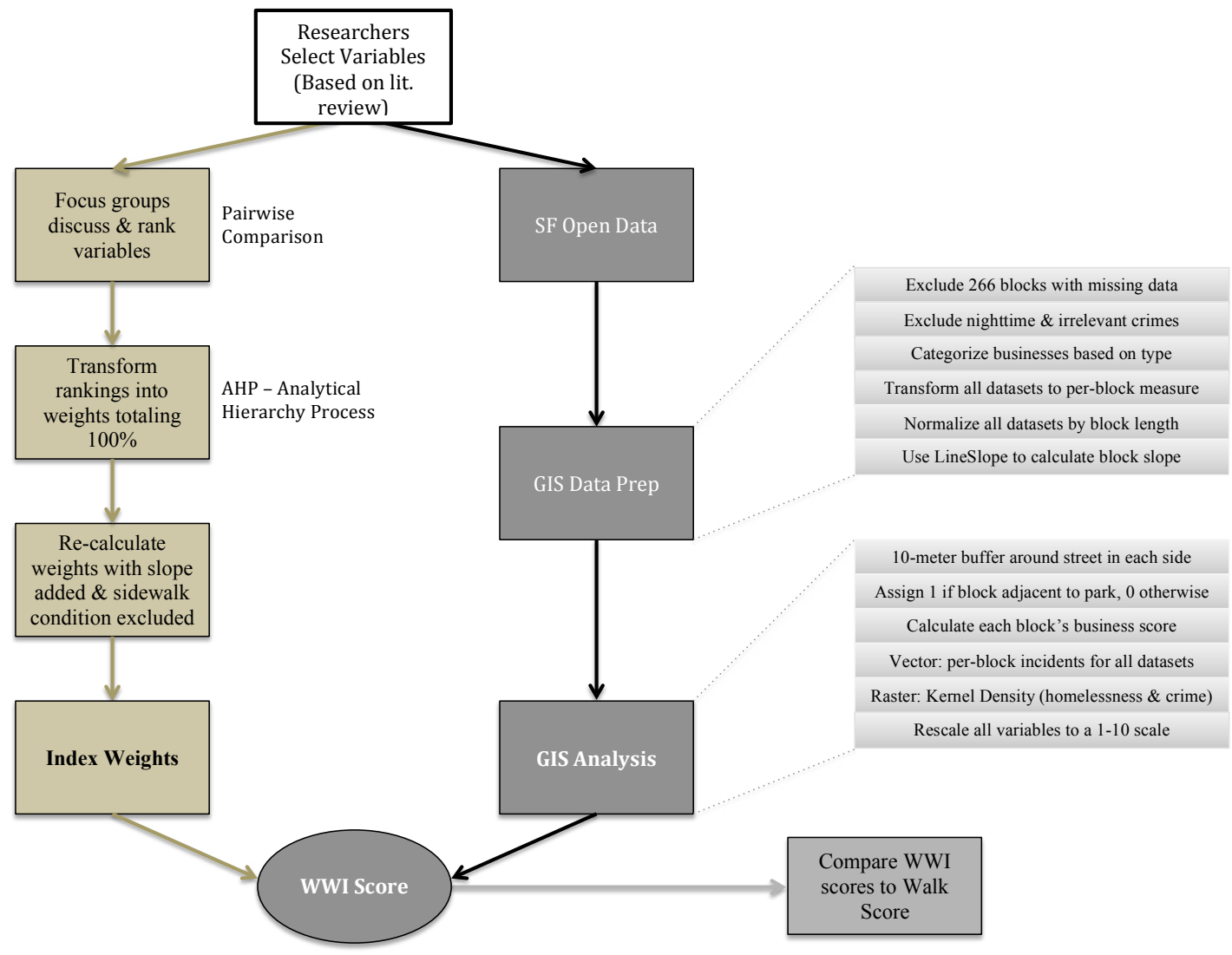

Figure 5. Women's Walkability Index step-by-step methodology

\subsection{GIS analysis}

A vector-based approach was used to analyze most variables, in order to capture their density at the city block level and provide a per-block index score. The rationale for this approach was twofold: first, the City of San Francisco reports much of its data at the block level rather than providing exact addresses; second, for many of the examined measures, like street cleaning requests, the intensity (i.e., density) of incidents for any given city block is presumably more meaningful to women pedestrians than the exact location of each incident.

First, a 10-meter buffer was added to the streets layer to capture only those incidents that occurred 10 meters from the center of the road in either side. The buffer distance was based on San Francisco's recommended street and sidewalk width of 17-18.3 meters (56-60 feet) (San Francisco Fire Department, n.d.; San Francisco Planning Department, 2010). Next, the number of incidents per block was calculated using a spatial join for each of the following variables: walkability-promoting businesses, walkability-inhibiting businesses, walkability-neutral businesses, parking spaces in off-street lots and garages, requests for street and sidewalk cleaning, reports of graffiti, and intersections with curb ramps. Parks were given a score of 1 if the block was immediately adjacent to a park, and a score of 0 otherwise, since the walkability-related benefits of parks appeared to only occur immediately adjacent to them, based on focus group discussions. The dataset for maximum speed limits was already in a per-block format so no further manipulation was needed.

For businesses, a new dataset was calculated based on the three categories of businesses (walkabilitypromoting, walkability-inhibiting, and neutral). The density per block of each of these three categories 
was multiplied by a weight selected to reflect each category's influence on walkability, under the assumptions that promoting and inhibiting businesses have the same magnitude of influence (in opposite directions), and that neutral businesses have half as much the influence as promoting or inhibiting businesses, because even if they are not themselves attractants, neutral businesses still contribute to a livelier street, which in turn contributes to walkability. The weights selected were therefore $40 \%$ each for promoting and inhibiting businesses, and $20 \%$ for neutral businesses.

Once the density per block was calculated for each of the datasets, attributes from all the different layers were joined into one master table, and the density-per-block measure for each variable was normalized by block length. This was done to neutralize the influence of exceptionally long blocks (i.e., a very long block may have more crimes reported on it simply because it has greater area in which crimes can occur rather than actually representing an unusually crime-dense block). To allow for comparison of metrics with different units and scales, data were then rescaled to a continuous 1-10 scale, with 10 representing the "best-case" scenario for the variable (supporting walkability) and 1 representing the "worst-case" scenario (impeding walkability). Most variables were rescaled using the Natural Breaks method (Jenks, 1967), based on ten natural breaks. For the nonlinear variables speed limit, parking garages, and slope rescaling was done manually (Figure 6).

\begin{tabular}{c|ccc}
\hline \multirow{2}{*}{ Score } & Speed Limit (MPH) & $\begin{array}{c}\text { Off-Street Parking Spaces } \\
\text { Per Block }\end{array}$ & Slope \\
\hline 1 & $>45$ & $>350$ & $>0.11$ \\
\cline { 2 - 4 } 3 & $36-45$ & $36-350$ & $0.09-0.11$ \\
\cline { 2 - 4 } 5 & $25-35$ & $11-35$ & $0.06-0.08$ \\
\cline { 2 - 4 } 8 & $16-25$ & $1-10$ & $0.03-0.05$ \\
\hline 10 & $=<15$ & 0 & $=<0.02$ \\
\hline
\end{tabular}

Figure 6. Manually classified categories for non-linear variables

As mentioned, slope analysis was done separately since the slope was not ranked in the prioritizing grid and was therefore not assigned a weight. The slope for each city block was calculated using the LineSlope Tool (Davis, 2014), which calculates the difference in elevation between the two edges of the block. This was done because some streets in San Francisco are cut into the side of hills, so while their slope based strictly on a DEM may seem steep, they can be relatively flat. Slopes were then reclassified manually into five categories informed by San Francisco's Walk First methodology for determining pedestrian activity (San Francisco Planning Department, 2011) and assigned scores of 0, 3, 5, 8 or 10 to allow for easy comparison with other datasets, with flat blocks receiving the highest score.

With the two remaining variables, crime and presence of homeless people or encampments, a raster approach was taken to account for the spillover effects of these variables, which may cause crime and homelessness in one block to "spill" outwards and affect women's walking in adjacent blocks, an effect that cannot be captured with vector analysis counts of incidents on a block-by-block basis. For example, small alleyways that have little or no crime or homelessness may be perceived to have similar characteristics to adjacent main streets that have high levels of crime or homelessness. For the raster analysis, the Kernel Density tool was used to calculate the density of crime reports and of requests for cleanup of encampments, carts, needles or human waste per 3-meter cell, at a 100-meter kernel search radius. 
The values in each raster cell centroid were extracted and clipped to the buffered streets layer, and then aggregated by block using a Spatial Join and Summary Statistics combination. These measures did not need to be normalized by block length, so they were rescaled into ten natural breaks and joined back to the master dataset.

Once the vector and raster sections of the analysis were combined, each variable's normalized and rescaled per-block density was multiplied by the weight assigned to it by the Analytic Hierarchy Process, and the complete index was added together resulting in a Women's Walkability Index (WWI) score between 1 and 10 for each block in San Francisco.

\subsection{Walk Score}

Once the index was completed and scores were available for every city block, the scores were compared to those generated by Walk Score. Since Walk Score provides point-specific scores (by exact address or latitude-longitude coordinates) and WWI provides a block-level score, block-midpoint latitude and longitude coordinates served as the basis for comparison. A basic JavaScript tool (Salzman, 2017) was built to use these midpoint coordinates to retrieve the corresponding walkability scores from Walk Score's API. Walk Scores were retrieved in March 2016. Spearman's Correlation test was used to examine the correlation between WWI scores and Walk Scores. This same test was also used to evaluate the correlation between crime and Walk Scores given previous study's observations about the relationship between Walk Score and crime levels as well as focus group feedback on the relative importance of this factor.

\section{$3 \quad$ Results}

\subsection{Focus group discussion}

Seventeen women from 13 different neighborhoods participated in focus group meetings. None of the women lived in the urban core areas of the city but many of them worked there and traveled there daily. Participant ages ranged from early twenties to late sixties with an average age of 37.1 and a median age of 36. Most participants had been long-time residents of the City and were very familiar with its layout and geography. According to focus group participants, crime and personal safety proved the most influential variables on women's walking, even during the daytime. Most participants stated that they would prefer walking on streets where other people are present, rather than on small side streets and alleys that felt deserted. Several participants noted that quiet streets are "eerie" or "unsettling." Some participants preferred quieter streets with fewer people but would only walk on such streets if they were familiar with them and had walked there before. Most participants were highly aware of their surroundings while walking and had adopted personal strategies to keep themselves safe from crime and threatening situations. Examples included avoiding walking under bridges or in alleys and small side streets, walking on the traffic side of the sidewalk so that they cannot be grabbed from within buildings or crevices between buildings, and crossing the street when approaching a group of men.

Homelessness was also very influential. Most participants only felt comfortable walking by homeless people when there were not many of them, or if they were familiar "neighborhood regulars." When this was the case, participants tended to view homeless individuals as neighbors and were not intimidated by their presence. However, there was a consensus that groups of homeless people, as well as homeless encampments, should be avoided entirely, partly because of personal safety issues and worrying about erratic, unpredictable behavior by the homeless people (and their dogs), and partly because some participants felt that they were intruding into the homeless individuals' personal space and disturbing their privacy. Most participants agreed that homeless encampments also affected their walking due to cleanliness and smell issues associated with encampments. 
Sidewalk cleanliness seemed to highly affect participants' walking. They differentiated between "normal city dirtiness" - some trash, animal feces, etc.—and "nasty" streets where the location and amount of garbage and trash suggest that the street is neglected and there are no "eyes on the street," indicating a possible threat to personal safety. Several participants also mentioned bad smells (mostly of human feces or urine) as major deterrents to walking. San Francisco has a relatively large homeless population ( 795 homeless individuals per 100,000 residents compared to an average of 479 among peer cities) (City and County of San Francisco Office of the Controller, 2017), which has drawn media and public attention as the city tries to deal with an increase in complaints of human feces, syringes and homeless encampments on city sidewalks (Smith, 2016), particularly in some areas usually considered highly walkable.

Most participants agreed that urban parks are an attractant in terms of walking and that they generally promote walkability, but there was a consensus around the need to avoid walking in or near parks at night or early in the morning. Even during the daytime, most women said they would not walk alone in larger parks with lots of hidden spots and remote trails, echoing previous studies on women's fear of crime in urban green spaces (Sreetheran \& Van Den Bosch, 2014).

Most women stated that they liked walking on "visually interesting" streets with businesses, particularly retail with interesting shop fronts, and food and beverage businesses, and would prefer to avoid blocks with "walkability-inhibiting" types of businesses such as liquor stores, auto shops and industrial uses. Two participants mentioned that when walking their dogs, they tend to avoid streets with multiple retail businesses due to high density of people, which makes walking their dogs more challenging. One participant noted that she tends to avoid commercial streets when walking with her toddler for the same reason, though she does prefer commercial streets when walking alone.

Vehicular traffic was a major cause for concern, and several participants tended to avoid major streets with many traffic lanes and high traffic volumes or high speed limits. Strategies for avoiding or minimizing the risks of vehicular traffic included changing routes and walking on smaller streets, walking facing oncoming vehicular traffic, and opting for streets with stop lights rather than stop signs. Some participants also noted that traffic noise and exhaust bothered them when walking on major streets. A few participants, particularly older ones, were also troubled by cyclists and preferred to refrain from walking on streets they knew to have a large volume of bicycle traffic, even when there were designated bike lanes present.

The four remaining variables — graffiti, off-street parking, curb ramps and sidewalk quality - were only discussed briefly as there was a consensus that these were relatively inconsequential in terms of their impact on women's daytime walking. Slope was also discussed; a few participants mentioned that hilly streets, while challenging to climb, might be safer or more pleasant to walk on since there are fewer crimes and fewer homeless people, but on the other hand are less appealing since fewer people walk on them, which makes them feel deserted and unsettling.

\subsection{Focus groups rankings and weights}

Participant rankings were quite consistent, with a majority of participants ranking crime and homelessness as the two most influential variables, followed, for the most part, by vehicular traffic and sidewalk cleanliness (not necessarily in that order). All but one participant ranked at least one of the two variables - crime and homelessness - in the top three. Graffiti and curb ramps were consistently ranked as the least important variables. Variation across participants' rankings was largest with regards to businesses, parks, and sidewalk quality, but these variables, too, were generally consistently ranked as of medium importance (Figure 7). 


\begin{tabular}{lc}
\hline Variable & Rank \\
\hline Fear of crime & 1 \\
\hline Presence of homeless people or encampments & 2 \\
\hline Street and sidewalk cleanliness & 3 \\
\hline Vehicular traffic volume & 4 \\
\hline Parks \& open space & 5 \\
\hline Type of businesses on the street & 6 \\
\hline Sidewalk quality* & 7 \\
\hline Off-street parking garages and parking lots & 8 \\
\hline Graffiti incidents & 9 \\
\hline Curb ramps & 10 \\
\hline Slope** & - \\
\hline$*$ Sidewalk quality had to be excluded from the GIS analysis due to data limitations \\
$* *$ Slope was not part of the prioritizing grid and was no ranked by focus group participants \\
\hline
\end{tabular}

Figure 7. Focus groups rankings of the ten variables

As mentioned in the Methods section, the sidewalk quality variable had to be excluded from the index since data for this variable was not available. And since participants did not rank slope, the index needed to be computed both with and without slope. Therefore, the AHP process used to transform the rankings into weights for the GIS analysis was repeated twice, to create two models. The first model excluded both sidewalk quality and slope, and the second model excluded sidewalk quality, but included slope. Variable weights do not vary significantly between the two models, nor do they differ significantly when all variables are taken into account (Figure 8). Under both models, crime and homelessness exert the strongest effects on women's walkability (about 31\%-37\% and 17\%-20\% of the total index score, respectively). 


\begin{tabular}{|c|c|c|c|}
\hline & \multicolumn{2}{|r|}{ Model 1} & \multirow{2}{*}{$\begin{array}{c}\text { Model } 2 \\
\text { Excluding } \\
\text { Sidewalk } \\
\text { Quality }\end{array}$} \\
\hline & $\begin{array}{c}\text { All } \\
\text { Variables }\end{array}$ & $\begin{array}{c}\text { Excluding } \\
\text { Slope \& } \\
\text { Sidewalk } \\
\text { Quality }\end{array}$ & \\
\hline A: Sidewalk Ouality & $4.5 \%$ & $0.0 \%$ & $0.0 \%$ \\
\hline B: Street \& Sidewalk Cleanliness & $9.7 \%$ & $10.2 \%$ & $9.7 \%$ \\
\hline C: Fear of Crime & $29.5 \%$ & $37.0 \%$ & $31.1 \%$ \\
\hline D: Presence of Parks & $8.3 \%$ & $8.9 \%$ & $8.5 \%$ \\
\hline E: Presence of Curb Ramps & $1.8 \%$ & $1.4 \%$ & $2.1 \%$ \\
\hline F: Homelessness & $17.3 \%$ & $20.3 \%$ & $17.5 \%$ \\
\hline G: Vehicular Traffic Volume & $8.7 \%$ & $9.1 \%$ & $8.8 \%$ \\
\hline H: Off-Street Parking & $2.9 \%$ & $2.9 \%$ & $3.4 \%$ \\
\hline I: Graffiti Incidents & $2.5 \%$ & $2.4 \%$ & $2.9 \%$ \\
\hline J: Types of Businesses & $7.2 \%$ & $7.8 \%$ & $7.6 \%$ \\
\hline K: Slope & $7.6 \%$ & $0.0 \%$ & $8.4 \%$ \\
\hline Total & $100.0 \%$ & $100.0 \%$ & $100.0 \%$ \\
\hline
\end{tabular}

Figure 8. Variable weights under the two models

Street and sidewalk cleanliness also proved highly important to women (around $10 \%$ of the index score), and these three variables combined (crime, homelessness and street cleanliness) accounted for about $58 \%-67 \%$ of the final index score. The presence of parks (around $8.5 \%$ ), the volume of vehicular traffic (about $9 \%$ ) and the type of businesses found on the street $(\approx 7.5 \%)$ were also important. The four remaining variables - graffiti, off-street parking, curb ramps and sidewalk quality - together accounted for only about $12 \%$ of the final index score when all variables are taken into account, or about $7 \%-8 \%$ when excluding sidewalk quality (Models 1 and 2). 


\begin{tabular}{|c|c|c|c|c|c|c|c|c|c|c|c|}
\hline & & 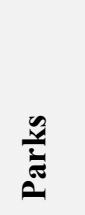 & 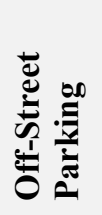 & 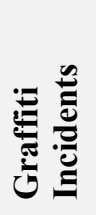 & 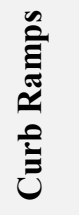 & 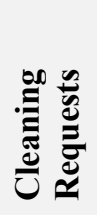 & 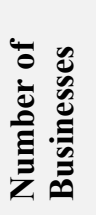 & 导 & 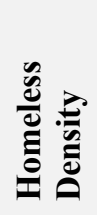 & $\frac{\check{0}}{\mathscr{\sigma}}$ & 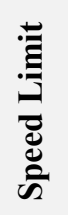 \\
\hline \multirow{2}{*}{ Parks } & Coefficient & 1.000 & $-.048^{* *}$ & $-.036 *$ & -.014 & $-.066^{* *}$ & $-.116^{* *}$ & $-.047^{* *}$ & $-.087^{* *}$ & $.030^{* *}$ & -.015 \\
\hline & Sig. (2-tailed) & . & .000 & .000 & .079 & .000 & .000 & .000 & .000 & .000 & .069 \\
\hline \multirow{2}{*}{$\begin{array}{c}\text { Off-Street } \\
\text { Parking }\end{array}$} & Coefficient & $-.048^{* *}$ & 1.000 & $.195^{* *}$ & $.022^{* *}$ & $.195^{* *}$ & $.215^{* *}$ & $.316^{* *}$ & $.249^{* *}$ & $-.199^{* *}$ & $.066^{* *}$ \\
\hline & Sig. (2-tailed) & .000 & & .000 & .009 & .000 & .000 & .000 & .000 & .000 & .000 \\
\hline \multirow{2}{*}{$\begin{array}{c}\text { Graffiti } \\
\text { Incidents }\end{array}$} & Coefficient & $-.036^{* *}$ & $.195^{* *}$ & 1.000 & $.134^{* * *}$ & $.429^{* * *}$ & $.295^{* *}$ & $.413^{* *}$ & $.420^{* *}$ & $-.138^{* *}$ & $.084^{* *}$ \\
\hline & Sig. (2-tailed) & .000 & .000 & . & .000 & .000 & .000 & .000 & .000 & .000 & .000 \\
\hline \multirow{2}{*}{$\begin{array}{c}\text { Curb } \\
\text { Ramps }\end{array}$} & Coefficient & -.014 & $.022^{* *}$ & $.134^{* *}$ & 1.000 & $.328^{* *}$ & $.263^{* *}$ & $.168^{* *}$ & $.117^{7^{*}}$ & $-.024^{* *}$ & $.088^{* *}$ \\
\hline & Sig. (2-tailed) & .079 & .009 & .000 & & .000 & .000 & .000 & .000 & .003 & .000 \\
\hline \multirow{2}{*}{$\begin{array}{l}\text { Cleaning } \\
\text { Requests }\end{array}$} & Coefficient & $-.066^{* *}$ & $.195^{* *}$ & $.429^{* *}$ & $.328^{* * *}$ & 1.000 & $.448^{* *}$ & $.522^{* *}$ & $.628^{* *}$ & $-.183^{* *}$ & $.141^{* *}$ \\
\hline & Sig. (2-tailed) & .000 & .000 & .000 & .000 & & .000 & .000 & .000 & .000 & .000 \\
\hline \multirow{2}{*}{$\begin{array}{c}\text { No, of } \\
\text { Businesses }\end{array}$} & Coefficient & $-.116^{* *}$ & $.215^{* *}$ & $.295^{* *}$ & $.263^{* *}$ & $.448^{* *}$ & 1.000 & $.425^{* *}$ & $.371^{* *}$ & $-.129^{* *}$ & $.019^{*}$ \\
\hline & Sig. (2-tailed) & .000 & .000 & .000 & .000 & .000 & . & .000 & .000 & .000 & .023 \\
\hline \multirow{2}{*}{$\begin{array}{l}\text { Crime } \\
\text { Density }\end{array}$} & Coefficient & $-.047^{* *}$ & $.316^{* *}$ & $.413^{* *}$ & $.168^{* *}$ & $.522^{* *}$ & $.425^{* *}$ & 1.000 & $.629^{* *}$ & $-.199^{* *}$ & $.075^{* *}$ \\
\hline & Sig. (2-tailed) & .000 & .000 & .000 & .000 & .000 & .000 & & .000 & .000 & .000 \\
\hline \multirow{2}{*}{$\begin{array}{c}\text { Homeless } \\
\text { Density }\end{array}$} & Coefficient & $-.087^{* *}$ & $.249^{* *}$ & $.420^{* *}$ & $.117^{* *}$ & $.628^{* *}$ & $.371^{* *}$ & $.629^{* *}$ & 1.000 & $-.245^{* *}$ & $.112^{* *}$ \\
\hline & Sig. (2-tailed) & .000 & .000 & .000 & .000 & .000 & .000 & .000 & . & .000 & .000 \\
\hline \multirow{2}{*}{ Slope } & Coefficient & $.030^{* *}$ & $-.199^{* *}$ & $-.138^{* *}$ & $-.024^{* *}$ & $-.183^{* *}$ & $-.129^{* *}$ & $-.199^{* *}$ & $-.245^{* *}$ & 1.000 & $-.112^{* *}$ \\
\hline & Sig. (2-tailed) & .000 & .000 & .000 & .003 & .000 & .000 & .000 & .000 & . & .000 \\
\hline \multirow{2}{*}{$\begin{array}{l}\text { Speed } \\
\text { Limit }\end{array}$} & Coefficient & -.015 & $.066^{* *}$ & $.084^{* *}$ & $.088^{* *}$ & $.141^{* *}$ & $.019^{*}$ & $.075^{* *}$ & $.112^{* *}$ & $-.112^{* *}$ & 1.000 \\
\hline & Sig. (2-tailed) & .069 & .000 & .000 & .000 & .000 & .023 & .000 & .000 & .000 & \\
\hline
\end{tabular}

Figure 9. Non-parametric correlations between variables_-Spearman's rho

The correlations between the variables used in the models were also examined. While many of the variables showed statistically significant correlations, these relationships varied in strength, with most correlations being of weak to moderate strength. The two strongest correlations, between crime and homelessness and between cleaning requests and homelessness, had Spearman's rho coefficient values of 0.629 and 0.628 , respectively (Figure 9).

$\underline{\text { Index results }}$

Both models had similar outcomes with few substantial differences in minimum, maximum or mean WWI score for San Francisco city blocks (Figure 10). 


\begin{tabular}{|c|c|c|}
\hline & Model 1 & Model 2 \\
\hline N (blocks scored) & 14,507 & 14,507 \\
\hline Min WWI Score & 3.44 & 4.07 \\
\hline Max WWI Score & 9.63 & 9.58 \\
\hline Mean WWI Score & 8.15 & 8.01 \\
\hline Standard Deviation & 0.96 & 0.83 \\
\hline
\end{tabular}

Figure 10. Descriptive statistics of the two models

Map 1 shows the aggregated WWI score for each city block based on Model 2 (the more extensive model, which excludes sidewalk quality but includes slope). High-walkability areas are shown in blue and low-walkability areas are shown in red. The city's Downtown, Tenderloin, and South of Market (SoMa) neighborhoods, all with relatively high prevalence of homelessness and crime, have the lowest overall WWI scores and create a large, continuous area of low walkability for women in the heart of San Francisco. Additional pockets of low walkability appear in other parts of the city, mostly in the eastern side, in areas with light-industrial activity, near freeway underpasses, and along large commercial corridors like Mission Street and Market Street, which are generally considered very walkable. Map 2 shows a hot and cold spot analysis (Getis \& Ord, 1992) of Model 2 WWI scores, where cold spots (marked blue) are statistically significant clusters of very low women's walkability scores and hot spots (marked red) are statistically significant clusters of very high walkability scores. This map attests to the positive effects of parks, open space and greenery on women's walkability, as hot spots of high walkability closely align with some of the city's open spaces, like Lake Merced in the southwest, Ocean Beach and Park Presidio Blvd going north from Lake Merced, and around the perimeter of Golden Gate Park in the northwest. 
Women's Walkability Index

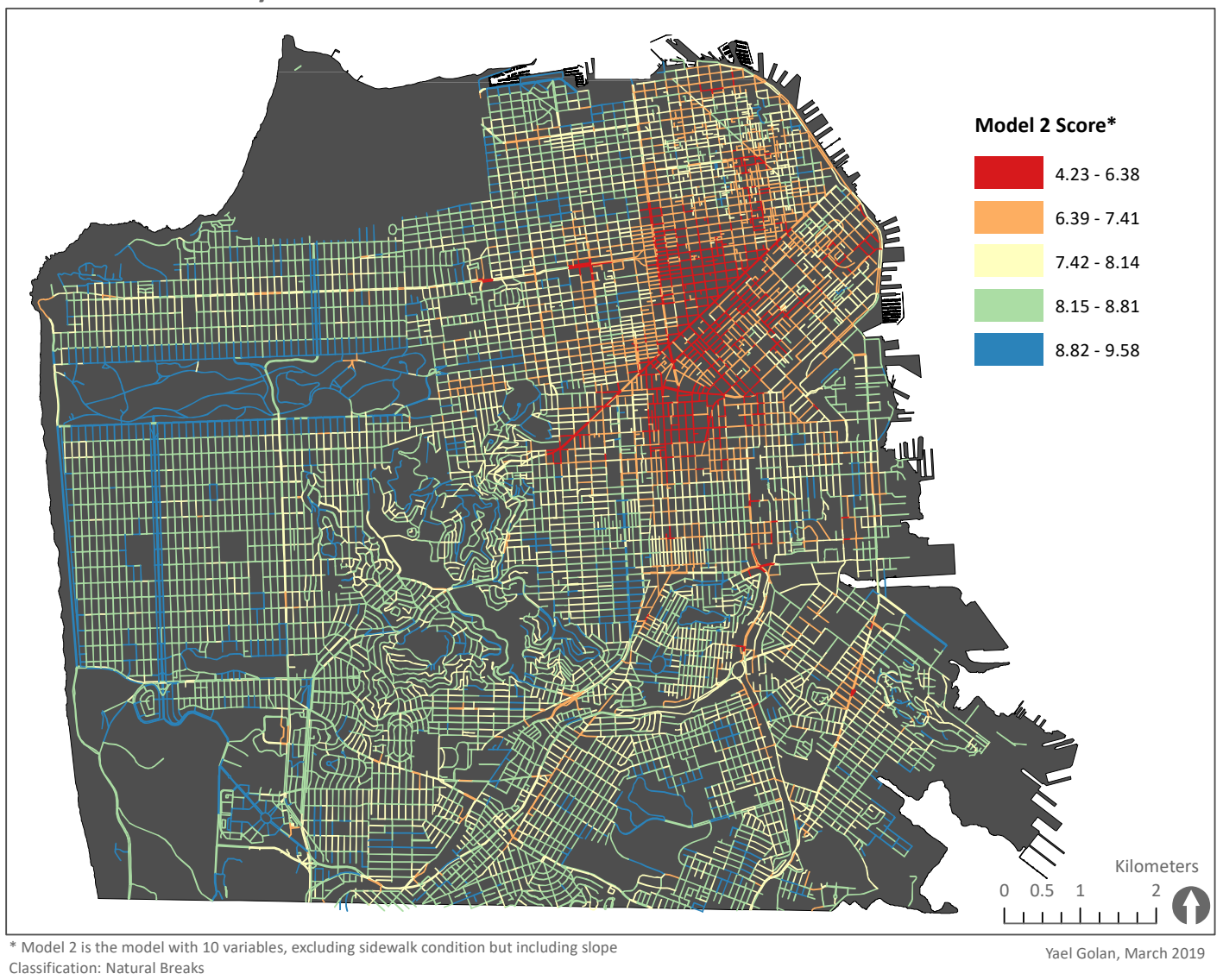

Map 1. Women's Walkability Index block scores—Model 2 


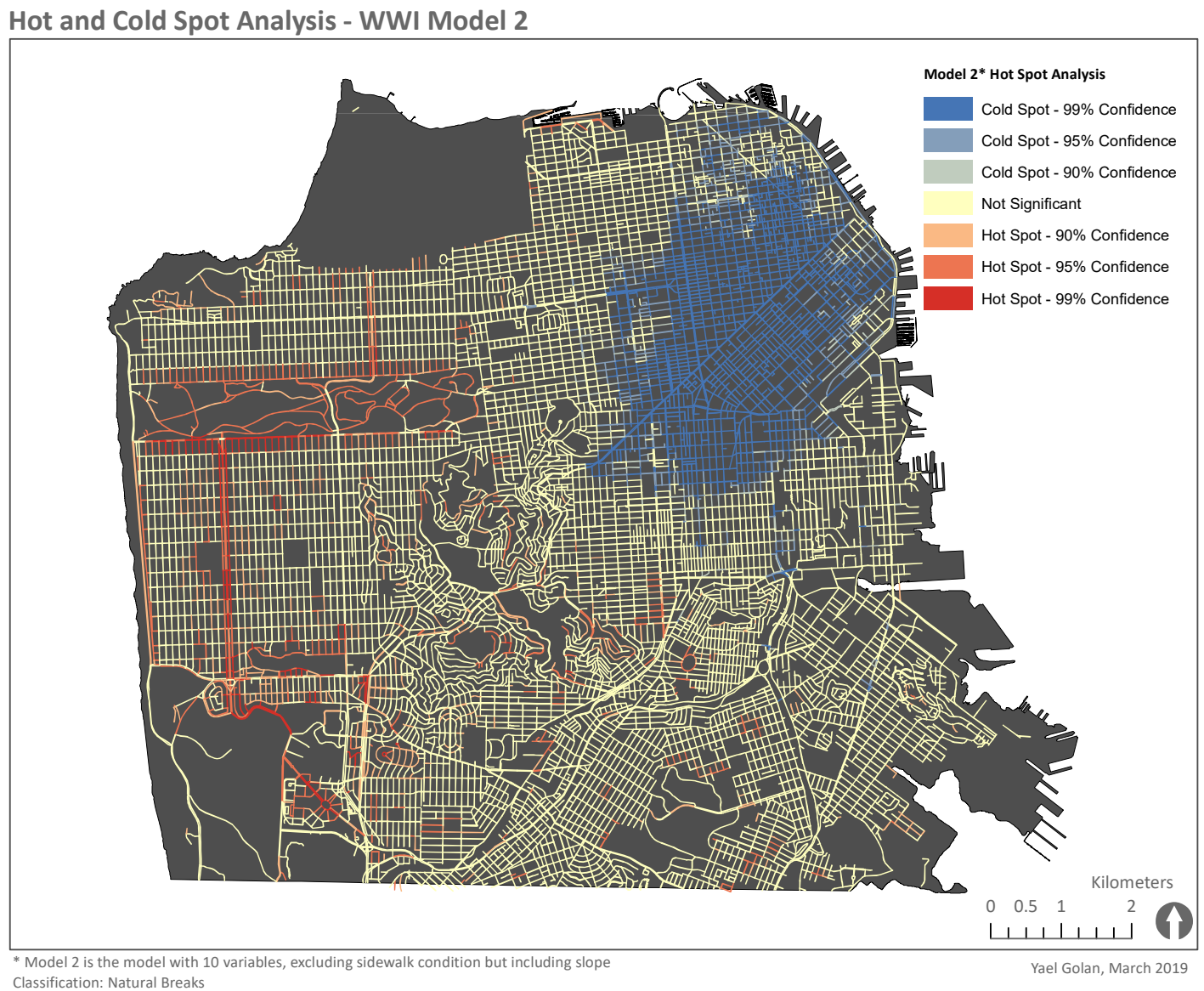

Map 2. Hot and cold spot analysis—-Model 2

\section{Walk Score Comparison}

Women's Walkability Index scores were examined against Walk Score for each of the 14,507 city blocks analyzed and for both models, by comparing the mid-block Walk Score to the corresponding block's WWI score. Both models showed a significant $(\mathrm{p}<0.01)$ moderate negative correlation with Walk Score, with Spearman's rho coefficients of -0.585 (model 1) and -0.525 (model 2) (Figure 11). Walk Score was also moderately positively correlated with crime (Spearman's rho value of $0.678 ; \mathrm{p}<$ $0.01)$.

\begin{tabular}{lc|cc}
\hline & \multicolumn{2}{c}{ Model 1 } & Model 2 \\
\hline \multirow{2}{*}{ Walk Score } & Correlation Coefficient & $-.585^{* * *}$ & $-.525^{* *}$ \\
\cline { 2 - 3 } & Sig. (2-tailed) & .000 & .000 \\
\cline { 3 - 3 } & $\mathrm{N}$ & 14,507 & 14,507 \\
\hline$* *$ Correlation is significant at the 0.01 level (2-tailed) & \\
\hline
\end{tabular}

Figure 11. Correlations between Walk Score and Women's Walkability Index 
WWI scores were transformed from their original 1-10 scale to a 1-100 scale to allow for easier comparison with Walk Score. Map 3 shows the absolute value differences between Walk Score and WWI scores, computed by subtracting the rescaled WWI score from the corresponding Walk Score for each block. Blue areas on this map indicate where indices agree (have similar scores). Red areas indicate large differences (in absolute values) between the two scores. Such areas include the Downtown, SoMa and Tenderloin neighborhoods in the southeast, which are considered extremely walkable by Walk Score, but have low WWI scores because of high crime and homelessness. Other areas where the indices disagree include Lake Merced and Ocean Beach on the western waterfront and the hilly neighborhoods around Mount Sutro, where lack of walking destinations drives Walk Scores down while low crime and homelessness prevalence and nearby open space drive WWI scores up; and areas with few roads, where lower intersection density and longer blocks are likely the reason for Walk Scores being lower than WWI scores.

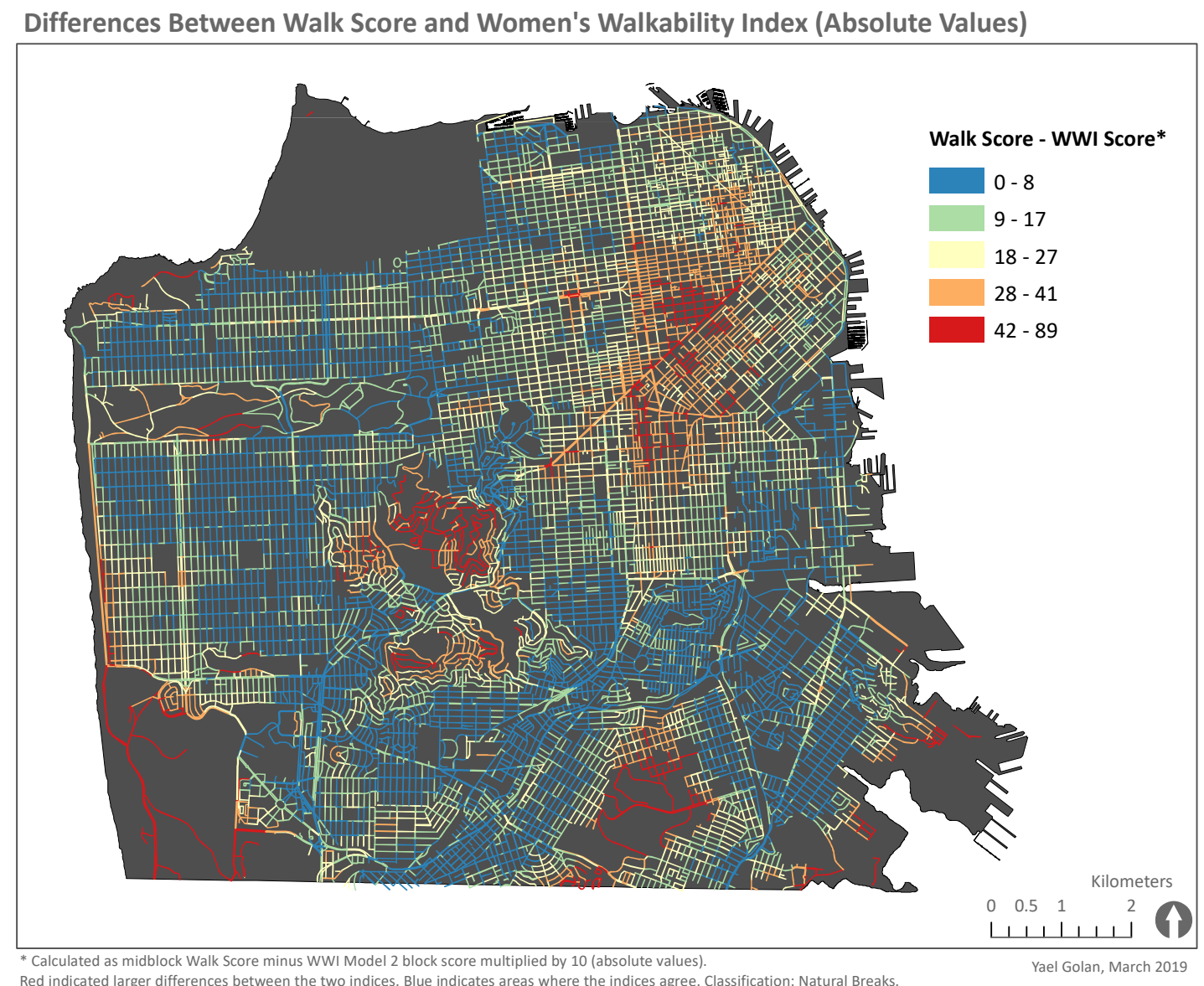

Map 3. Differences between WWI score and Walk Score

\section{Discussion}

This study aimed to answer two research questions: Which variables most influence women's propensity to walk? And Does the leading walkability index, Walk Score ${ }^{\oplus}$ reflect women's walkability?

In regard to the first research question, the results of this study reaffirm the importance of fear of crime as an influence, if not the influence, on women's walkability, even during the daytime. By focusing specifically on daytime walkability, this study attempted to capture some of the additional factors and 
considerations influencing women's walking behavior. However, focus group discussions and variable rankings by focus group participants suggested that fear of crime remains the number one factor among many factors affecting women when they decide where, when and how to walk, regardless of time of day. The idea that fear of crime is significantly less influential on women's daytime walking than it is at night seems to be questionable, at least in San Francisco. While women may differ in the types of situations they find threatening, there was a consensus among participants that a sense of personal safety is a prerequisite for women's walking. It is not surprising, then, that three of the four top-ranking variables were related to sense of safety: crime, homelessness and vehicular traffic (ranked numbers 1, 2, and 4, respectively).

Studies exploring the relationship between crime and walking often encounter a disassociation between respondents' sense of neighborhood safety and actual crime incidents: fear of crime is many times only weakly associated with actual crime (Foster \& Giles-Corti, 2008). By using both subjective (focus group discussions) and objective (reported crime incidents) data, this study was able to minimize this limitation. Focus group participants discussed their perceived safety in a more general way and were not asked to rank specific locations in the city by how safe they perceived them to be. Instead, participants were asked to choose the elements in the built environment that most influenced them when walking during the daytime, and their choices were used to create a ranking and weighting system which later served as the basis for analysis of objective crime data. This minimized the potential for perceptionrelated biases.

Interestingly, some of the participants said they felt safer and much less vulnerable when running, or when cycling, than when walking. The perception that walking was the most vulnerable mode of transportation in the eyes of some women was intriguing and should be further investigated.

The presence of homeless people on a street block does not automatically deter women from walking there. Rather, as focus group participants pointed out, it is a matter of familiarity and magnitude. While the "familiarity" effect of homeless people could not be accounted for in this index, the issue of magnitude was addressed in the GIS analysis, by using a density measure for homelessness. Many of the participants explained their inclination to avoid walking near homeless people as an attempt to avoid unpredictable situations, echoing Valentine's (1989) claim that women's fear in public spaces is basically a fear of unpredictable and uncontrollable behaviors by strangers. More importantly, Valentine's assertion that women perceive only men as strangers is also echoed in this study. As the women in one of the focus groups agreed - after a long discussion of fear of crime and homelessness, objectification of women in the public sphere, and catcalling by construction workers - that what they are really trying to avoid are groups of men:

Participant A: "I would avoid construction sites because of catcalling... I'm not afraid of them, just disgusted by male objectification of women"

Participant B: "Yeah, just leave me alone, just let me walk down the street"

Participant C: "Depends on the size of construction. Small contractors who live in the city and raise daughters here are more respectful"

Participant D: "I get catcalled by homeless people and would prefer construction workers over homeless (people)"

Participant E: "So I think the point is that it's not necessarily construction workers, just groups of men. Even a group of men in suits would bother me"

Participant A: "I agree, I'd avoid groups of men" (Most other participants nodded or mumbled in agreement)

Street and sidewalk cleanliness (ranked third) and the presence of parks or open spaces (ranked fifth) both point to the importance of aesthetics to women when walking, in line with previous studies that found women's walking to be strongly associated with neighborhood aesthetics (Pelclová et al., 
2013), more so than men's walking (Van Dyck et al., 2013). However, the relationship between parks, greenery and open spaces and women's walking is convoluted. Previous studies have shown that parks and badly placed bushes and greenery (Koskela \& Pain, 2000) and deserted open spaces (Valentine, 1989) can deter women's walking, but this study found small urban parks to be a major attractant to women's walking, at least during the daytime. Most women in this study would not avoid parks and greenery, and in fact would actively seek green areas to walk in or near during the daytime, with the exception of very large parks with remote trails, and large wilderness-like open spaces.

As for vehicular traffic, previous research has shown that women are more likely than men to view the presence of traffic as an important factor when walking (Weinstein Agrawal, Schlossberg, \& Irwin, 2008) and are more likely than men to list reasons related to the amount of traffic as deterrents to walking (Clifton \& Dill, 2005). Indeed, focus group participants ranked vehicular traffic as the fourth most influential factor on walking, and extensively discussed their fear of vehicular traffic and major thoroughfares, noise from traffic and exhaust fumes. Interestingly, some participants were almost as concerned about bicycle traffic. Future research into the relationship between walkability and bicycling may shed some light on this issue.

While mixed-use streets with retail businesses are generally shown to promote walkability (Pelclová et al., 2013; Talen \& Koschinsky, 2013), the presence of businesses on the street seems to have a mixed effect on focus group participants. Most participants did state that having "eyes on the street" (Jacobs, 1961) and seeing other people on the street when walking were important to them, in accordance with previous research by Weinstein Agrawal et al. (2008). However, at least during the daytime, this seems to be an issue of personal preference, with a small minority of focus group participants saying they preferred walking on quieter streets and avoiding the hustle and the bustle of busy commercial streets. The choice of busy vs. quiet streets also depends, according to focus group discussions, on who is walking (walking with dogs or small children seems to favor quieter streets, while walking alone favors busy commercial streets), the time of day (rush hour vs. mid-day) and mood. In terms of the types of businesses that promote or deter walking, participants mentioned liquor stores, mini-marts that sell liquor and snacks, auto shops and large industrial/manufacturing businesses as deterrents to walking, and restaurants, coffee shops and small boutique shops as attractants. Other types of establishments believed to promote walkability for women, like churches and shopping malls (Clifton \& Livi, 2005), were not discussed.

Other variables examined in this study, which were found in previous studies to influence women's walking, like parking lots (Valentine, 1989; Clifton \& Livi, 2005), graffiti (Craig, Brownson, Cragg, \& Dunn, 2002), sidewalk conditions (Clifton \& Dill, 2005; (Handy, 2007) and curb ramps (Clifton \& Livi, 2005) turned out to be less important to focus group participants and had a smaller effect on index score. These four variables combined accounted for only $10.1 \%-11.7 \%$ of a block's final score, or $6.7 \%-8.3 \%$ when excluding sidewalk quality.

Based on focus group rankings, the least walkable areas for women in San Francisco are in the northeastern part of the city. Additional pockets of low women's walkability are found along large commercial streets and around highway intersections and underpasses. These areas received low walkability rankings because they are high-crime, high-homelessness and relatively dirty (i.e., have large numbers of street and sidewalk cleaning requests), three variables that together account for $58.3 \%$ (Model 2) to $67.5 \%$ (Model 1) of the entire walkability score. Interestingly, the lowest-walkability areas according to the WWI are also some of the most densely populated, mixed-use, business-rich areas of San Francisco, most popular with tourists and locals. If WWI scores accurately represent the reality of women's walking then some of the most widely accepted conventions about what kind of areas promote walking may be inaccurate when it comes to women.

The most consistently walkable areas for women are concentrated on the western side of the city, mostly as a result of relatively low crime and low homeless densities in these areas. Throughout the city, low-crime and low-homelessness areas adjacent to parks receive very high WWI scores. 
It seems that the answer to the second research question, Does the leading walkability index, Walk Score ${ }^{\oplus}$ reflect women's walkability? is no. Based on focus group discussions and variable rankings, the most influential factor on women's walking is fear of crime, accounting for $31.1 \%$ - 37\% of the total WWI score. Since Walk Score's algorithm does not take crime into account, it is hard to claim that Walk Score accurately reflects women's walkability. Although Walk Score has been validated by academics as a reliable walkability measure (Duncan, et al., 2012; Manaugh \& El-Geneidy, 2011), it has also been criticized for ignoring crime, and one study found it to be positively correlated with crime (Carr et al., 2010). Like Carr et al. (2010), this study found a statistically significant positive correlation of moderate strength (Spearman's rho value of 0.678; $\mathrm{p}<0.01$ ) between Walk Score and crime reports in San Francisco. Walk Score also ignores other built environment variables that were part of WWI, such as traffic, topography and neighborhood aesthetics (Duncan et al., 2012). Additionally, Walk Score was found to best capture walkability at a large spatial scale of 1,600 meters (1 mile) (Duncan et al., 2012), which is much larger than the average city block length in San Francisco (about 120 meters, or just under 400 feet), the spatial scale analyzed by WWI. As a large-scale, nationally applied, "one size fits all" walkability index, Walk Score may not be nuanced enough to detect relative walkability within a generally walkable place like San Francisco, as WWI does.

Given these differences between Walk Score and WWI, and especially given the importance of crime in WWI and its absence from Walk Score, it is no surprise that the two indices show a statistically significant negative correlation of moderate strength (Spearman's rho values of -0.525 to -0.585 , depending on WWI model). The Tenderloin neighborhood, for example, has some of the lowest WWI block scores in the city, however its Walk Score is 99 (out of 100) making it in the top 5\% of neighborhoods in the city in terms of walkability.

This study has limitations. First and foremost, the index weights are based on the subjective preferences of focus group participants and repeating this study with other participants in San Francisco, or with participants in other locations, might yield different weights. The participant recruitment method may have introduced a self-selection bias, with women who are particularly interested in walking more likely to volunteer. Since none of the participants lived in the urban core areas of the city, where crime and homelessness are most pronounced, it could be argued that participants were more sensitive to these issues than women who do live in the urban core. However, many of the participants work downtown and travel there daily. Focus group discussions around crime and homelessness may have influenced participants' perception of these variables' importance. Some of the datasets used in the analysis, particularly homelessness and street and sidewalk cleanliness, are based on data reported to the city by residents (i.e., SF311 reports). Such reports may be more likely in certain neighborhoods, or by certain residents, than others, and it is impossible to know whether absence of reporting indicates absence of occurrences, or whether occurrences are simply under-reported in certain places. The exclusion of nighttime crimes from analysis may have created a bias, since it may very well be that areas known to have many nighttime crimes become less walkable for women during the daytime too, even if crimes are not committed during the day.

Finally, the Women's Walkability Index models walkability in an additive way, assuming a decisionmaking process that considers all walkability-influencing factors simultaneously. However, anecdotal evidence from focus group discussions suggests that women's decision-making process may be comprised of several binary decisions, where some minimum factors - like an acceptably low level of crime or homelessness - must be met, before other factors of lower importance can be weighed additively. Future research should perhaps explore the idea of a "minimal threshold" for women's walking.

This study was a first attempt at creating a women-specific walkability index. Future studies should repeat this study either with a larger group of women or in other cities to identify issues of broader significance. Additional variables may also need to be included to fully account for women's unique walk- 
ing preferences. To better understand women's walkability, future research could also explore women's daily routes, especially as they relate to familial and caregiving duties, which in many families are still being carried out primarily by women.

\section{$5 \quad$ Conclusions}

The Women's Walkability Index is heavily influenced by crime, homelessness and sidewalk cleanliness. It seems that the Index under-values the presence of businesses on the street, which is traditionally believed to increase walkability, leading to low walkability scores in areas usually considered highly walkable and highly appealing for pedestrians. Still, there is no reason to suspect that the index significantly over-represents the importance of fear of crime, homelessness and cleanliness, and anecdotal evidence suggests that this is, indeed, a fair representation of the most important considerations for women pedestrians.

Most of the variables comprising the Women's Walkability Index have a negative association with walking, thus WWI could be interpreted as an index that captures deterrents to walking. Walk Score, on the other hand, is heavily influenced by the proximity of walking destinations, i.e., attractants. Perhaps WWI should be used to inform Walk Score, or vice versa. A walkability model integrating both Walk Score and WWI could offer the most accurate representation of women's walkability to date.

This is a first attempt at creating a women-specific walkability index. Future iterations of this index may provide more insight into women's walking. This study's main contributions to the walkability discussion are its focus on women's walkability, and its mixed-method approach, combining the added value of hearing from women first-hand what matters to them, with the analytical capabilities of GIS software, which provides the opportunity for a large-scale, replicable analysis. Another major contribution of this study is the understanding that women's daytime walking is not much different than nighttime walking in that it, too, is governed by fear of crime and the search for a sense of personal safety. This understanding should guide policy makers, urban planners, landscape architects and walkability advocates in designing urban environments that are safe and welcoming for women. Policy makers hoping to improve walkability for women should focus on designing neighborhoods and streets that feel safe. Streets and building designs should enable human interaction and maximize the number of "eyes on the street" while eliminating or minimizing the number of spaces that feel deserted or unsafe. Traffic calming measures on major pedestrian streets, including a better separation between cyclists and pedestrians and certain limitations on freight movement; prioritizing underground parking garages over large off-street parking lots which reduce the street's vibrancy and may be seen as a hazard by women; and adding greenery and shrubbery to urban streets and sidewalks to make them feel more inviting could also enhance walkability for women.

Future research should expand this study's scope to look at other cities and geographies, additional variables not included here, and nighttime walking. The notion of women's decision-making process as a set of binary decisions resulting in a "minimal threshold" necessary for women's walking should also be further investigated. Finally, the idea that women perceive walking as the most vulnerable means of transport, expressed by some focus group participants, is an interesting concept that warrants further investigation.

Understanding the mechanisms and built-environment features that influence women's walking, especially in a walkable city like San Francisco, can have important implications for cities trying to improve women's pedestrian experience, increase overall walkability, and create better pedestrian environments that encourage walking over driving for both genders. As many cities around the world become increasingly more interested in minimizing vehicular usage, improving walkability for women may go a long way in achieving such goals. 


\section{References}

Brookfield, K., \& Tilley, S. (2016). Using virtual street audits to understand the walkability of older adults' route choices by gender and age. International Journal of Environmental Research and Public Health, 13(11), 1061. doi.org/10.3390/ijerph13111061

Calise, T. V., Heeren, T., DeJong, W., Dumith, S. C., \& Kohl, H. W. (2013). Do neighborhoods make people active, or do people make active neighborhoods? Evidence from a planned community in Austin, Texas. Preventing Chronic Disease, 10, E102. oi.org/10.5888/pcd10.120119

Carr, L., Dunsiger, S., \& Marcus, B. (2010). WalkScoreTMas a global estimate of neighborhood walkability. American Journal of Preventive Medicine, 39(5), 460-3. doi.org/10.1016/j.amepre.2010.07.007

Cervero, R., \& Duncan, M. (2003). Walking, bicycling, and urban landscapes: Evidence from the San Francisco Bay Area. American Journal of Public Health, 93(9), 1478-1483. doi.org/10.2105/ AJPH.93.9.1478

Clifton, K. J., \& Dill, J. (2005). Women's travel behavior and land use: Will new styles of neighborhoods lead to more women walking? Transportation Research Board Conference Proceedings, 35, 89-99.

Clifton, K. J., \& Livi, A. D. (2005). Gender differences in walking behavior, attitudes about walking, and perceptions of the environment in three Maryland communities. Research on Women's Issues in Transportation, 2, 79-88.

Cortright, J. (2009). Walking the walk: How walkability raises home values in U.S. cities. CEO's for Cities. Retrieved from http://www.icr.org/article/3110/293/

Craig, C. L., Brownson, R. C., Cragg, S. E., \& Dunn, A. L. (2002). Exploring the effect of the environment on physical activity. American Journal of Preventive Medicine, 23(2), 36-43. doi.org/10.1016/ S0749-3797(02)00472-5

Davis, J. D. (2014). LineSlope.py [Esri ArcPy geoprocessing script]. San Francisco, CA: Institute for Geographic Information Science, San Francisco State University.

Diao, M., \& Ferreira, J. (2014). Vehicle miles traveled and the built environment: Evidence from vehicle safety inspection data. Environment and Planning A, 46(12), 2991-3009. doi.org/10.1068/ a140039p

Duncan, D. T., Aldstadt, J., Whalen, J., \& Melly, S. J. (2012). Validation of Walk Scores and transit scores for estimating neighborhood walkability and transit availability: A small-area analysis. GeoJournal, 78(2), 407-416. doi.org/10.1007/s10708-011-9444-4

Durand, C., Andalib, M., Dunton, G., Wolch, J., \& Ma, P. (2011). A systematic review of built environment factors related to physical activity and obesity risk: Implications for smart growth urban planning. Obesity Reviews, 12(5), e173-e182. doi.org/10.1111/j.1467-789X.2010.00826.x

Foster, S., \& Giles-Corti, B. (2008). The built environment, neighborhood crime and constrained physical activity: An exploration of inconsistent findings. Preventive Medicine, 47(3), 241-251. doi. org/10.1016/j.ypmed.2008.03.017

Frank, L. D., Sallis, J. F., Conway, T. L., Chapman, J. E., Saelens, B. E., \& Bachman, W. (2006). Many pathways from land use to health: Associations between neighborhood walkability and active transportation, body mass index, and air quality. Journal of the American Planning Association, 72(1), 75-87. doi.org/10.1080/01944360608976725

Getis, A., \& Ord, J. K. (1992). The analysis of spatial association by use of distance statistics. Geographical Analysis, 24(3), 189-206. doi.org/10.1111/j.1538-4632.1992.tb00261.x

Handy, S. L. (2007). Community design and travel behavior: Exploring the implications for women. UC Davis: Institute of Transportation Studies (UCD). Retrieved from https://escholarship.org/uc/ item/8jx6x28p 
Jacobs, J. (1961). The death and life of great American cities. New York: Vintage Books.

Kerr, J., Norman, G., Millstein, R., Adams, M. A., Morgan, C., Langer, R. D., \& Allison, M. (2014). Neighborhood environment and physical activity among older women: Findings from the San Diego cohort of the Women's Health Initiative. Journal of Physical Activity and Health, 11(6), 10701077. doi.org/10.1123/jpah.2012-0159

Koschinsky, J., \& Talen, E. (2015). Affordable housing and walkable neighborhoods: A national urban analysis. Cityscape: A Journal of Policy Development and Research, 17(2), 13-56.

Koskela, H., \& Pain, R. (2000). Revisiting fear and place: Women's fear of attack and the built environment. Geoforum, 31(2), 269-280. doi.org/10.1016/S0016-7185(99)00033-0

Leinberger, C., \& Alfonzo, M. (2012). Walk this way: The economic promise of walkable places in metropolitan Washington, DC. Washington, DC: Brookings Institution.

Leslie, E., Coffee, N., Frank, L., Owen, N., Bauman, A., \& Hugo, G. (2007). Walkability of local communities: Using geographic information systems to objectively assess relevant environmental attributes. Health \& Place, 13(1), 111-22. doi.org/10.1016/j.healthplace.2005.11.001

Loukaitou-Sideris, A. (2006). Is it safe to walk? Neighborhood safety and security considerations and their effects on walking. Journal of Planning Literature, 20(3), 219-232. doi. org/10.1177/0885412205282770

Manaugh, K., \& El-Geneidy, A. (2011). Validating walkability indices: How do different households respond to the walkability of their neighborhood? Transportation Research Part D: Transport and Environment, 16(4), 309-315. doi.org/10.1016/j.trd.2011.01.009

Owen, N., Humpel, N., Leslie, E., Bauman, A., \& Sallis, J. F. (2004). Understanding environmental influences on walking; Review and research agenda. American Journal of Preventive Medicine, 27(1), 67-76. doi.org/10.1016/j.amepre.2004.03.006

Pain, R. (2001). Gender, race, age and fear in the city. Urban Studies, 38(5-6), 899-913. doi. org/10.1080/00420980120046590

Park, A., \& Calvert, T. (2008). A social agent pedestrian model. Computer Animation And Virtual Worlds, 19(August), 331-340. doi.org/10.1002/cav

Park, A., Clare, J., Spicer, V., Brantingham, P. L., Calvert, T., \& Jenion, G. (2012). Examining context-specific perceptions of risk: Exploring the utility of "human-in-the-loop" simulation models for criminology. Journal of Experimental Criminology, 8(1), 29-47. doi.org/10.1007/s11292-0119132-x

Pelclová, J., Frömel, K., \& Cuberek, R. (2013). Gender-specific associations between perceived neighborhood walkability and meeting walking recommendations when walking for transport and recreation for Czech inhabitants over 50 years of age. International Journal of Environmental Research and Public Health, 11(1), 527-536. doi.org/10.3390/ijerph110100527

Saaty, T. L. (2008). Relative measurement and its generalization in decision making why pairwise comparisons are central in mathematics for the measurement of intangible factors the analytic hierarchy/ network process. Revista de La Real Academia de Ciencias Exactas, Fisicas y Naturales. Serie A. Matematicas, 102(2), 251-318. doi.org/10.1007/BF03191825

Salzman, Z. (2017). Walkscore-client-js [Computer software]. https://github.com/zivzs/walkscore-client-js

San Francisco Fire Department. (n.d.). 5.01 Street widths for emergency access. Fire Department. Retrieved from http://sf-fire.org/501-street-widths-emergency-access

San Francisco Planning Department. (2010). Ch. 4, Approach: Designing great streetscapes. San Francisco better streets. Policies and guidelines for the pedestrian realm. San Francisco. Retrieved from http:// www.sf-planning.org/ftp/BetterStreets/docs/Draft_BSP_for_Adoption_4_Designing_Great_ Streetscapes.pdf 
San Francisco Planning Department. (2011). Walk first. Where people walk: Methodology for determining Pedestrian activity Factors. San Francisco: SF Planning Department.

SFMTA. (2014). San Francisco Municipal Transportation Agency (SFMTA) travel decisions survey 2014. San Francisco: SFMTA.

Smith, J. (2016, November 2). Explosion of complaints of feces and syringes across San Francisco streets. Daily Mail Online. Retrieved from http://www.dailymail.co.uk/news/article-3897480/Explosion-complaints-feces-syringes-San-Francisco-streets-city-s-homeless-epidemic-grows.html

Sreetheran, M., \& Van Den Bosch, C. C. K. (2014). A socio-ecological exploration of fear of crime in urban green spaces-A systematic review. Urban Forestry and Urban Greening. doi.org/10.1016/j. ufug.2013.11.006

Sugiyama, T., Salmon, J., Dunstan, D. W., Bauman, A. E., \& Owen, N. (2007). Neighborhood walkability and TV viewing time among Australian adults. American Journal of Preventive Medicine, 33(6), 444-449. doi.org/10.1016/j.amepre.2007.07.035

Talen, E., \& Koschinsky, J. (2013). The walkable neighborhood: A literature review. International Journal of Sustainable Land Use And Urban Planning, 1(1), 42-63.

Talen, E., \& Koschinsky, J. (2014). Compact, walkable, diverse neighborhoods: Assessing effects on residents. Housing Policy Debate, 24(4), 717-750. http://doi.org/10.1080/10511482.2014.900102

U.S. Department of Transportation. (2011). 2009 National Household Travel Survey. Retrieved from http://nhts.ornl.gov/2009/pub/stt.pdf

Vale, D. S., Saraiva, M., \& Pereira, M. (2015). Active accessibility: A review of operational measures of walking and cycling accessibility. Journal of Transport and Land Use, 9(1), 209-235. doi.org/10.5198/ jtlu.2015.593

Valentine, G. (1989). The geography of women's fear. Area, 21(4), 385-390.

Van Dyck, D., Cerin, E., Conway, T. L., De Bourdeaudhuij, I., Owen, N., Kerr, J., ... Sallis, J. F. (2013). Perceived neighborhood environmental attributes associated with adults' leisure-time physical activity: Findings from Belgium, Australia and the USA. Health \& Place, 19, 59-68. doi.org/10.1016/j. healthplace.2012.09.017

Van Dyck, D., Cerin, E., De Bourdeaudhuij, I., Salvo, D., Christiansen, L. B., Macfarlane, D., ... Sallis, J. F. (2015). Moderating effects of age, gender and education on the associations of perceived neighborhood environment attributes with accelerometer-based physical activity: The IPEN adult study. Health and Place, 36, 65-73. doi.org/10.1016/j.healthplace.2015.09.007

Walk Score. (n.d.). Walk Score methodology. Retrieved from http://www.walkscore.com/methodology. shtml

Walk Score. (2016). Most walkable cities in the United States, Canada, and Australia on Walk Score. Retrieved from https://www.walkscore.com/cities-and-neighborhoods/

Weinstein Agrawal, A., Schlossberg, M., \& Irvin, K. (2008). How far, by which route and why? A spatial analysis of pedestrian preference. Journal of Urban Design, 13(1), 81-98. doi. org/10.1080/13574800701804074

Zahran, S., Brody, S. D., Maghelal, P., Prelog, A., \& Lacy, M. (2008). Cycling and walking: Explaining the spatial distribution of healthy modes of transportation in the United States. Transportation Research Part D: Transport and Environment, 13(7), 462-470. doi.org/10.1016/j.trd.2008.08.001 